\title{
The effect of outpatient physical therapy intervention on pelvic floor muscles in women with urinary incontinence
}

Mara R. Knorst ${ }^{1}$, Thais L. Resende ${ }^{1}$, Thaís G. Santos ${ }^{2}$, José R. Goldim ${ }^{3}$

\begin{abstract}
Objective: To assess the effect of a weekly, short-term physical therapy intervention on the pelvic floor muscles and urinary incontinence (UI) among patients of the public health system. Method: Quasi-experimental before-and-after study. Clinical history and function evaluation were performed using perineal bidigital maneuvers and perineometry. The intervention consisted of transvaginal electrical stimulation and pelvic floor kinesiotherapy. Data were analyzed using the paired t test or Wilcoxon signed-rank test, Pearson product-moment correlation coefficient or Spearman's rank correlation coefficient. A value of $\mathrm{P}<0.05$ was considered significant. Results: Eight-two women $55.1 \pm 10.9$ years-old were evaluated. Mixed urinary incontinence (MUI), stress urinary incontinence (SUI) and urge urinary incontinence (UUI) were observed in $52.4 \%, 36.6 \%$ and $11 \%$, respectively. The length of UI was 6.0 years (3.0-10). Approximately 13.64 physical therapy sessions were held on average. There was no difference in perineometry measurements following the intervention $(40.6 \pm 24.1$ versus $41.7 \pm 25.4, \mathrm{P}=0.098)$. Muscle function significantly increased $(\mathrm{P}<0.01)$ in the bidigital maneuver. The patients reported being continent or satisfied with the treatment in $88.9 \%$ of cases. Conclusions: The results demonstrated an increase in muscle function and the attainment of urinary continence or treatment satisfaction in most cases.
\end{abstract}

Keywords: physical therapy; women's health; muscular strength; electrical stimulation therapy; exercise therapy. Article registered in the Brazilian Clinical Trials Registry (Registro Brasileiro de Ensaios Clínicos, REBEC), number RBR-3P5S66.

\section{HOW TO CITE THIS ARTICLE}

Knorst MR, Resende TL, Santos TG, Goldim JR. The effect of outpatient physical therapy intervention on pelvic floor muscles in women with urinary incontinence. Braz J Phys Ther. 2013 Sept-Oct; 17(5):442-449. http://dx.doi.org/10.1590/ S1413-35552012005000117

\section{Introduction}

Urinary incontinence (UI) affects over 200 million people worldwide and is considered a public health problem ${ }^{1}$. It is classified as stress UI (SUI) if there is involuntary loss of urine when coughing or sneezing; urge UI (UUI) if there is an abrupt and sudden urge to urinate that cannot be postponed; or mixed UI (MUI) if it is associated with both situations mentioned above, which may also result from emotional aspects ${ }^{2}$.

The factors involved in the pathophysiology of UI include the following: extra-abdominal pressure on the bladder neck, the presence of a short urethra, decreased estrogen and injury of the sphincter mechanism, pudendal nerve, fascia and pelvic floor muscles (PFM) ${ }^{1}$.

UI is often associated with aging ${ }^{3}$. However, urinary problems are not natural or exclusive consequences of aging ${ }^{3,4}$ as mild to moderate UI is more common in younger women, whereas older women have moderate to severe $\mathrm{UI}^{5}$. UUI occurs in extreme age groups, and SUI is observed in women in their $50 \mathrm{~s}^{6}$. Notwithstanding, some changes related to aging occur in the lower urinary tract, even in the absence of disease, including decreased detrusor muscle contraction strength, bladder capacity and ability to postpone urination. Involuntary contractions of the vesical muscle and increased post-void residual volume and tissue aging also occur ${ }^{6}$, which may lead to muscle hypotrophy, decreasing the ability of the pelvic floor muscles (PFM) to contribute effectively to urinary continence?

The clinical history and physical examination are part of the routine assessment of incontinent women to gather the vesicle history; reproduce and characterize incontinence ${ }^{8}$; assess the motility, urinary loss, vaginal atrophy, genital prolapse ${ }^{9}$,

\footnotetext{
${ }^{1}$ School of Nursing, Nutrition and Physical Therapy, Pontifícia Universidade Católica do Rio Grande do Sul (PUCRS), Porto Alegre, RS, Brazil

${ }^{2}$ School of Medicine, PUCRS, Porto Alegre, RS, Brazil

${ }^{3}$ Institute of Geriatrics and Gerontology, PUCRS, Porto Alegre, RS, Brazil

Received: 07/20/2012 Revised: 01/07/2013 Accepted: 03/15/2013
} 
and pelvic support using the Valsalva maneuver with an empty bladder; and to exclude other pelvic diseases and neurological disorders ${ }^{10}$. Palpation of the vaginal canal enables the assessment of the level of contraction of the perineal muscles using different scales ${ }^{8,11,12}$ and teaches patients the correct PFM contraction ${ }^{13}$.

The conservative treatment is performed using techniques aimed at strengthening the PFM, including strengthening exercises, electrical stimulation, biofeedback and the use of vaginal cones ${ }^{14}$.

PFM training is indicated to strengthen the support of pelvic organs and to improve the closing mechanism of the urethral sphincter. The pelvic muscle work in SUI aims to improve the support muscle function during stress and teaches women to contract the muscle before and during stress, when the intra-abdominal pressure increases, including coughing. In UUI, the training aims to inhibit the detrusor contraction reflex ${ }^{15}$.

The conservative procedure should be the first choice treatment for the different causes of UI, starting with kinesiotherapy, and if it does not lead to the expected results, transvaginal electrotherapy should be considered ${ }^{8}$. Surgical treatment is an invasive resource, which may be accompanied by complications, has no guaranteed success and may be followed by relapse ${ }^{7}$.

Kegel ${ }^{16}$ emphasized the importance of supervision and encouragement in the treatment of patients with UI and recommended weekly check-ups. He reported that restoration of tone and muscle function could occur 20 to 60 days after the start of treatment ${ }^{1}$.

In Brazil, a country where the public health system faces chronic funding problems ${ }^{17}$, UI affects 30 to $43 \%$ of women ${ }^{7,15}$, generating the need to seek lowcost, low-risk forms of evaluation and treatment with proven efficacy and to make such measures accessible to public health system users. Therefore, the present study was developed with the objectives of assessing the effect of short-term, weekly physical therapy on PFM and UI and of comparing two methods of functional assessment of the PFM in public health system patients.

\section{- Method}

This is a quasi-experimental before-and-after-type study conducted at São Lucas Hospital (Hospital São Lucas, HSL), Pontifical Catholic University of Rio Grande do Sul (Pontifícia Universidade
Católica do Rio Grande do Sul, PUCRS), Porto Alegre, Rio Grande do Sul (RS), Brazil. The study was conducted between 2006 and 2011 and was approved by the PUCRS Research Ethics Committee under record 06/03194. The patients signed informed consent forms.

Eighty-two women with the medical (clinical) diagnosis of UI (SUI, MUI and UUI) were included in the study, consecutively referred from the HSL-PUCRS urogynecology outpatient clinic for physical therapy care. According to the care protocol of the urogynecology outpatient clinic, women with UI are only forwarded to physical therapy, and thus were only available for the present study, after three months without of unsuccessful home exercises to strengthen the pelvic muscles (fifteen repetitions, three times/day), guided by the medical staff.

The patients who performed any additional type of physical therapy, who started any type of structured or planned physical activity other than the exercises planned in the protocol, or those who submitted to surgery for the correction of UI during the study period were excluded. Patients with diseases including severe heart or lung disease, neurological diseases or malignancies were also excluded.

The study was divided into three stages: initial evaluation, intervention and final evaluation. All evaluations and interventions were performed at the HSL-PUCRS Physical Therapy Department. Each patient's procedures during the initial evaluation and final evaluation were performed by the same examiner, who did not have access to the data from the first evaluations during the final evaluation.

The initial evaluation, which consisted of a clinical history and pre-treatment measurements (perineometry and functional evaluation of the PFM), were performed during the first meeting before the patient was submitted to the intervention. Up to fifteen sessions (one per week) were performed in the intervention stage using transvaginal electrical stimulation and perineal exercises. Once the patient reported satisfaction with the results of the treatment and explicitly declared that she would not return, the sessions were discontinued, and she was reevaluated. Therefore, not all patients completed a maximum of 15 sessions. This procedure was adopted in light of the findings of a pilot study conducted by the authors, wherein women would no longer return once they considered themselves satisfied with the gains resulting from treatment. In the final evaluation, in addition to the same procedures of the initial assessment, the level of patient satisfaction with the 
treatment was examined based on four categories: no loss of urine (continence), satisfaction with the treatment (satisfaction), improvement (improvement), or no improvement as a result of the intervention (no improvement). This outcome (the level of patient satisfaction with the treatment) was chosen because the cure or improvement of symptoms reported by women with UI was identified as a primary outcome to be used in studies evaluating the effect of therapeutic interventions in that population ${ }^{18}$.

For the clinical history, data were gathered on age, education level, marital status, type and length of UI, situations of urine loss, amount of urine loss, number of pregnancies, type of delivery, episiotomy, menopausal status, obesity, prolapse, constipation, and performance of physical activity.

A digital perineometer was used (Kroman - T.I.U. - KG 40; São Paulo/SP/Brazil) which had a sensor for measuring pressures ranging from 0 to $1.75 \mathrm{cmH} 2 \mathrm{O}$. The test was conducted three times, and the highest value was used as the reference.

The functional evaluation of the pelvic floor was performed by bidigital maneuver with the patient in the supine position and lower limbs flexed. The patient was asked to contract and maintain the PFM contraction around the examiner's finger. The ability of that muscle to contract was graded based on the Ortiz' scale ${ }^{12}$, which grades the vaginal occlusion pressure and levator ani muscle contraction with values from zero to five, where zero represents the absence of muscle contraction and five represents a strong contraction sustained for more than five seconds.

The intervention involved Kinesiotherapy and transvaginal electrical stimulation. Kinesiotherapy consisted of PFM activation exercises using a ball and elastic band. The exercises performed were hip abduction and adduction (supine position and sitting) and pelvic bridge (supine). All exercises involved isotonic and isometric contractions (maintained for six seconds), with a series of ten repetitions for each type of exercise used.

The electrotherapy was performed for ten minutes using a device (Dualpex 961 URO model; manufacturer QUARK - Piracicaba, SP, Brazil) connected to an electrode inserted into the vagina, whose intensity was set according to the patient's tolerance, reaching a maximum current of $60 \mathrm{~mA}$. The current parameters varied according to the type of UI: Heterodyne $2 \mathrm{~K} / 10 \mathrm{~Hz}$ was used for UUI; and Kots $2 \mathrm{~K} / 50 \mathrm{~Hz}$, for SUI. The previous parameters were used interchangeably for MUI; that is, they received current with a frequency of $10 \mathrm{~Hz}$ (UUI) in one week and of $50 \mathrm{~Hz}$ (SUI) in the other.

Data analysis was performed using the statistical software SPSS 11.0. Data distribution was assessed using the Kolmogorov-Smirnov test. The before-andafter comparison was performed using the paired $t$ test for variables with normal distribution and Wilcoxon signed-rank test for asymmetric variables. The association between variables was examined using the Spearman's rank correlation coefficient. A value of $\mathrm{P}<0.05$ was considered significant.

\section{Results}

The demographic and clinical characteristics of the 82 patients are shown in Table 1. Half of the patients had between two to four pregnancies, and there were two nulliparous women in the total sample.

The patients performed on average 13.64 physical therapy sessions (range: 5-15).

Table 1. Sample characteristics.

\section{Variables}

Total $(\mathbf{n}=82)$

Age (years)

$55.1 \pm 10.9$

Married*

Complete or incomplete primary education*

Residing outside POA*

Type of incontinence*

MUI

SUI

UUI

Duration of incontinence (years)

Median (interquartile range)

$6.0(3.0-10)$

Loss in jets and drops*

Pregnancies (number)

Median (interquartile range)

Type of delivery

Normal (number of women)

Cesarean (number of women)

Episiotomy*

Prolapse*

Menopause*

Constipation*

*Data presented as n(\%) MUI: mixed urinary incontinence; SUI: stress urinary incontinence; UUI: urge urinary incontinence; POA: Porto Alegre, Brazil. 
Regarding the results of the PFM function evaluation (Table 2), no statistically significant difference was found in the two measurements performed using the perineometer, while the post physical therapy intervention measurements by the bidigital maneuver yielded significantly higher values than the initial ones $(\mathrm{P}<0.01)$.

After the intervention, $88.9 \%$ of the patients reported being continent or satisfied with the treatment (Figure 1). In comparing the distribution between the type of incontinence and the patients' satisfaction, no statistically significant association was found ( $>0.05)$, indicating an independent relationship between both variables. However, the frequency distribution demonstrates that $60.0 \%$ $(n=18)$ of 30 patients with SUI reported being satisfied, whereas $30.0 \%(\mathrm{n}=9)$ reported being continent. Approximately $48.6 \%(n=17)$ of the patients with MUI reported being satisfied, and $37.1 \%$ $(n=13)$ reported being continent. Continent patients predominated $(71.4 \% ; n=5)$ in the group with UUI.

The values observed in the perineometry were associated with the bidigital test measurements (Table 3), wherein the correlations (before $=0.57$; after $=0.59$ ) were positive and statistically significant $(\mathrm{P}<0.001)$.

\section{Discussion}

The results observed demonstrate that the most prevalent form of UI was mixed urinary incontinence (52.4\%), followed by SUI (36.6\%). These results corroborate data published by Figueiredo et al. ${ }^{7}$, who also evaluated women from the Brazilian public health system in a similar age group as the participants of this study. In contrast, Isherwood and

Table 2. The values of perineometry and bidigital tests obtained before and after the physical therapy intervention.

\begin{tabular}{cccc}
\hline \multicolumn{1}{c}{ Measurements } & \multicolumn{2}{c}{ Assessment period } & P \\
& Before & After & \\
Perineometry & & & \\
$\begin{array}{l}\text { Mean } \pm \text { standard } \\
\text { deviation }\end{array}$ & $40.6 \pm 24.1$ & $41.7 \pm 25.4$ & $0.098^{*}$ \\
$\begin{array}{l}\text { Minimum - Maximum } \\
\text { Bidigital test }\end{array}$ & $4-100$ & $9-100$ & \\
$\begin{array}{l}\text { Median (interquartile) } \\
\text { Minimum - Maximum }\end{array}$ & $4(3-5)$ & $4(4-5)$ & $<0.001 \S$ \\
\hline
\end{tabular}

*Student t-test for paired samples; §: Wilcoxon test.
Rane $^{19}$ reported a higher prevalence of SUI. This discrepancy between results is most likely explained by those researchers' recruitment of patients who exhibited urine loss due to stress and a lower age group than the present study patients.

We have also observed in our study that $50 \%$ of the subjects exhibited a time of incontinence ranging from three to ten years, corroborating the finding by Lewis $^{20}$, who reported that $75 \%$ of the 827 women with UI in their study took approximately three years to seek medical attention and physical therapy. Women with mild and moderate degrees of incontinence do not seek help, nevertheless, the search for treatment increases in the post-menopausal, when the degree of urinary loss increases ${ }^{8}$. However, the long period of time between the onset of urinary loss and the search for help not only results in worsening of the loss itself but also of the patients' quality of life. According to different authors, many women are unaware that UI

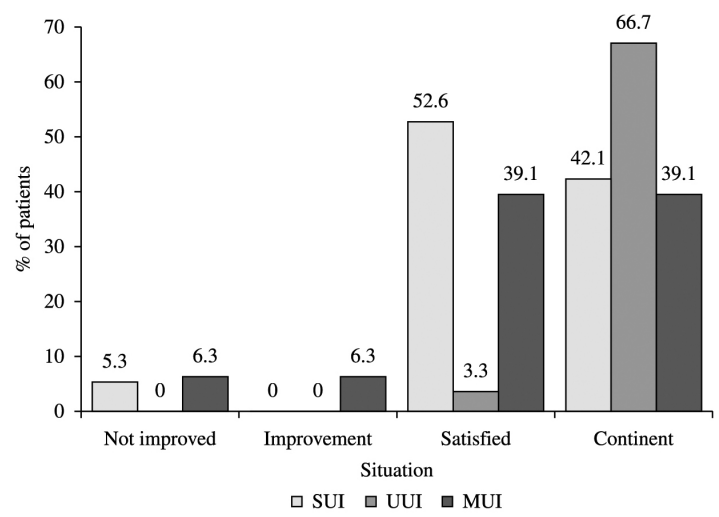

Figure 1. Distribution of the type of urinary incontinence with respect to patients' treatment satisfaction. SUI: stress urinary incontinence, UUI: urge urinary incontinence and MUI: mixed urinary incontinence.

Table 3. Relationship between results of the bidigital test and of perineometry obtained in the assessments performed before and after the physical therapy intervention.

\begin{tabular}{ccccc}
\hline & \multicolumn{3}{c}{ Perineometer } \\
$\begin{array}{c}\text { Bidigital } \\
\text { test }\end{array}$ & $\begin{array}{c}\text { Before } \\
\text { Coefficient } \\
(\mathbf{r})^{*}\end{array}$ & $\mathbf{p}$ & $\begin{array}{c}\text { Coefficient } \\
(\mathbf{r})^{*}\end{array}$ & $\mathbf{p}$ \\
Before & 0.569 & $<0.001$ & 0.468 & $<0.001$ \\
After & 0.364 & 0.001 & 0.591 & $<0.001$ \\
\hline *Spearman's correlation coefficient.
\end{tabular}


is treatable and consider it a natural result of the aging process $^{4,20}$. Such findings may explain the delayed search for a treatment for UI observed in this study and in that by Lewis ${ }^{20}$.

In the present study, approximately $32 \%$ of the subjects reported constipation. Constipation may stimulate bladder receptors, which may reduce its contractility and cause incomplete bladder emptying, a common complaint among women with UI ${ }^{8}$. Therefore, the importance of treating constipation alongside the treatment for UI is clear because the risk for all types of UI increases with constipation ${ }^{21}$.

In our study, $75.1 \%$ of the subjects reported urine losses in drops and jets. A similar result was found by Figueiredo et al. ${ }^{7}$, wherein $46 \%$ of the women reported losses in jets, and $28 \%$ reported losses in drops. Given that the urinary loss volume in SUI is usually small (droplets), this fact could explain the results of our study since most of the patients had a diagnosis of SUI and MUI. The literature emphasizes that the greater the volume of urine loss, the greater the negative effects on patient' lives ${ }^{22}$.

According to Neumann and Morrison ${ }^{23}$, improvement in muscle function resulting from the conservative treatment of UI leads to a better pelvic viscera positioning, which may lead to a reduction in the mass present inside the vaginal canal, thereby causing a reduction in the size of the prolapse, which, in turn, may lead to lower readings recorded by the perineometer in the post-treatment period. This finding may explain the fact that, despite a significant difference observed in the values of the bidigital maneuver and the patients' reports of having achieved continence, there was no statistically significant difference between the perineometer measurements obtained before and after therapeutic intervention, as $56.8 \%$ of subjects in the present study had prolapse.

Hundley et al. ${ }^{11}$ compared the use of perineometer with the bidigital maneuver in the evaluation of PFM function and reported similar levels of reproducibility and a strong linear correlation $(0.66>r<0.71)$ between the two measurements used. In our study, although the reproducibility was not examined because of its design, the correlation coefficients obtained were similar $(0.57>\mathrm{r}<0.59)$. Hundley et al. ${ }^{11}$ also reported a greater interobserver variability in the data obtained using the bidigital test. Due to this finding, in the present study all volunteers were examined by the same researcher at the initial and final phases of the treatment. This methodological precaution is particularly important as it has been shown that the final ratings from assessments performed by different evaluators presented significant differences ${ }^{8}$.

Although the Royal College of Obstetricians and Gynecologists (RCOG) reports that the use of PFM digital assessment still lacks scientific evidence, their expert advice is that the determination of the contractile capacity of the PFM may direct treatment decisions and that this assessment can be used to determine the effect of physical therapy intervention ${ }^{8}$. Furthermore, perineometry, regarded as the most objective measure, exhibits similar levels of reliability and accuracy if the measurements are conducted by the same observer on different occasions and if all observers are trained to conduct the measurements ${ }^{10}$, albeit at a much higher cost. The cost of the device ( $\mathrm{R} \$ 880.00)$ and its maintenance, as well as the longer time and greater labor involved in the process, must be considered, with the exception of the expenses common to both methods (gloves, lubricant and condom). Therefore, the results of the present study and those from previous studies reported in literature ${ }^{11,19}$ confirm the clinical use of the bidigital maneuver because it is a making it the instrument of choice for use in public health for determining the contractile capacity of the PFM, which guides the physical therapy treatment and the effect of this intervention.

There are several indications in the international literature regarding the frequency and length of treatment sessions for UI. In our study, we performed a single, weekly session of treatment because most subjects lived in the State hinterland and were dependent on free public transportation and/or could not afford to bear the costs of travel to our unit more times per week. Bo et al. ${ }^{24}$ indicate daily sessions of electrical stimulation for 30 minutes and 12 series of contractions for the pelvic floor. The $\mathrm{RCOG}^{8}$ suggested three months of exercises repeated three to four times daily and, if necessary, application of electrical stimulation two to three times per week, lasting 15 to 30 minutes. However, the results of the present study demonstrate that satisfactory gains may be reached through sessions of much shorter duration and lower frequency: this study's subjects attended an average of 13.6 weekly sessions, with ten minutes of electrostimulation and approximately 15 minutes of kinesiotherapy, with no indication for additional exercises. Despite the lower frequency and shorter 
duration of the treatment program of the present study, the success rate was similar to that obtained in other studies: $88.9 \%$ of subjects reported being continent or satisfied with the treatment undertaken, requiring no other type of additional treatment. These results corroborate those found by Herrmann et al. ${ }^{25}$, who reported cure or improvement in $81.7 \%$ of the women with UI following treatment. Other authors reported a cure rate of $84 \%$ in women with different types of UI after training the pelvic floor ${ }^{18,21}$. Therefore, the success rate in the present study falls within the success rate ranges described in the international literature, despite the lower frequency and shorter duration of treatment sessions.

In our study, we found that the success rate varied among the different types of UI, as has been described in previous studies ${ }^{25,26}$. Approximately $90 \%$ of the 30 patients with SUI reported being satisfied or continent. This result is similar to that found by Barroso et al. ${ }^{27}$, wherein $88 \%$ of the women with SUI reported cure or satisfaction with the result reached. Approximately $80 \%$ of the patients with MUI treated with electrical stimulation were satisfied in a study conducted by Amaro et al. ${ }^{28}$. Superior results were found in the present study, wherein $86.1 \%$ of patients reported being satisfied or continent.

Seven of the nine patients with UUI in the present study completed the study reaching continence, whereas another study on women with the same type of UI reported lower success rates, with a reduction of episodes of urinary urgency in $52.4 \%$ of patients who performed electrical stimulation and in $57.1 \%$ of patients who performed perineal exercises ${ }^{26}$.

These high success rates obtained with the conservative treatment of UI explain the position of the $\mathrm{RCOG}^{8}$ in suggesting that the primary surgical treatment for UI should only be considered when conservative treatment fails or if the patient declines to perform it. Thus, given the high success rates obtained with the conservative treatment, it becomes the first indication in the treatment of UI. The pelvic floor exercises are a low-cost, low-risk treatment and, when necessary, may include transvaginal electrical stimulation, as seen in this study, with proven efficacy even when conducted in short weekly sessions.

Significant technological resources will not be required to implement this treatment program in public health units; instead, it will require the presence of a physical therapist trained to conduct the evaluation and correct treatment for such dysfunction. The implementation of this program would meet the National Policy on Primary Care (Política Nacional de Atenção Básica) and the principles and guidelines of the National Policy for Comprehensive Healthcare for Women (Política Nacional de Atenção Integral à Saúde da Mulher) ${ }^{17}$. Furthermore, this treatment program would avoid the patients' travel from the interior of the state to the capital and its inherent costs, as occurred with $62.4 \%$ of the present study subjects, who had to be directed to a reference unit specialized in that treatment to successfully conduct a simple treatment that could be held in their home town.

Considering the possible abnormal and harmful functioning that this condition brings to health and quality of life of those who are affected by $\mathrm{it}^{20}$, the results observed in this study clearly reinforce the need to conduct preventive studies on UI, as well as the implementation of a strengthening pelvic floor exercise program for pregnant women and all other women. Thus, based on the results found in this study, the physical therapy treatments proposed could easily be implemented within the primary healthcare system, given its low complexity, the low cost of the bidigital test and treatment, and the high success rate reached. The treatment could be started with PFM exercises, which could be developed in groups, subsequently adding transvaginal electrical stimulation if necessary. Therefore, the cost and length of sessions could be even further reduced.

In conclusion, a treatment program with shortduration, weekly sessions resulted in the increase in pelvic floor muscle function and urinary continence or satisfaction with treatment for most women studied. The bidigital maneuver exhibited better results than the perineometer in detecting increased muscle function and continence resulting from the outpatient physical therapy.

\section{References}

1. Zanetti MR, Castro RA, Rotta AL, Santos PD, Sartori M, Girão MJ. Impact of supervised physiotherapeutic pelvic floor exercises for treating female stress urinary incontinence. Med J. 2007;125(5):265-9.

2. Abrams P, Cardoso L, Fall M, Griffiths D, Rosier P, Ulmsten U. The standardisation of terminology of lower urinary tract function: report from the standardisation sub-committee of International Continence Society. Urology. 2003;61(1):37-49. http://dx.doi.org/10.1016/ S0090-4295(02)02243-4 
3. Dos Reis RB, Cologna AJ, Martins ACP, Paschoalin EL, Tucci S Jr, Suaid HJ. Incontinência urinária no idoso. Acta Cir Bras. 2003;18(supl5):47-51.

4. Ko Y, Lin SJ, Salmon JW, Bron MS. The impact of urinary incontinence on quality of life of the elderly. Am J Manag Care. 2005;11(4 Suppl):S103-11. PMid:16161383.

5. Hannestad YS, Rortveit G, Sandvik H, Hunskaar S. A community-based epidemiological survey of female urinary incontinence: the Norwegian EPINCONT study. Epidemiology of Incontinence in the County of NordTrondelag. J Clin Epidemiol. 2000;53(11):1150-7. http:// dx.doi.org/10.1016/S0895-4356(00)00232-8

6. Bent AE, Ostergard DR, Cundiff GW, Swift SE. Ostergard: Uroginecologia e disfunções do assoalho pélvico. $5^{\mathrm{a}}$ ed. Rio de Janeiro: Guanabara Koogan; 2006.

7. Figueiredo EM, Lara JO, Cruz MC, Quintão DMG, Monteiro MVC. Perfil sociodemográfico e clínico de usuárias de Serviço de Fisioterapia Uroginecológica da rede pública. Rev Bras Fisioter. 2008;12(2):136-42. http:// dx.doi.org/10.1590/S1413-35552008000200010

8. Adams E, Bardsley A, Crumlin L, Currie I, Evans L, Haslam J. Urinary incontinence the management of urinary incontinence in women. RCOG Press at the Royal College of Obstetricians and Gynaecologists; 2006 [cited 2008 Oct 28]. Available from: http://www.nice.org. uk/nicemedia/pdf/CG40fullguideline.pdf.

9. Cardozo L, Staskin D. Textbook of female urology and urogynecology. 2nd ed. London: Informa Healtcare; 2006.

10. Feldner JR, Sartori MGF, Lima GR, Baracat EC, Girão MJBC. Diagnóstico clínico e subsidiário da incontinência urinária. Rev Bras Ginecol Obstet. 2006;28(1):54-62. http://dx.doi.org/10.1590/S0100-72032006000100010

11. Hundley AF, Wu JM, Visco AG. A comparison of perineometer to brink score for assessment of pelvic floor muscle strength. Am J Obstet Gynecol. 2005;192(5):158391. PMid:15902162. http://dx.doi.org/10.1016/j. ajog.2004.11.015

12. Ortiz $\mathrm{O}$. Valoración dinâmica de la disfunción perineal da classificación. Boletim de La Sociedad Latino Americana de Uroginecologia y Cirurgia vaginal. 1994;1(2):7-9.

13. Uyar Y, Baytur YB, Inceboz U. Perineometer and digital examination for assessment of pelvic floor strength. Int J Gynaecol Obstet. 2007;98(1):64-5. PMid:17466302. http://dx.doi.org/10.1016/j.ijgo.2007.03.015

14. Schoueri J, Ramos LR, Papaléo Netto M. Crescimento populacional: Aspectos Demográficos e Sociais. In: Carvalho ET F ${ }^{\circ}$, Papaléo $\mathrm{M} \mathrm{N}^{\circ}$, Editores. Geriatria - Fundamentos, Clínica e Terapêutica. São Paulo: Atheneu; 2000. p. 9-29.

15. Guarisi T, Pinto AM No, Osis MJ, Pedro AO, Paiva LH, Faundes A. Incontinência urinária entre mulheres climatéricas brasileiras: inquérito domiciliar. Rev Saude Publica. 2001;35(5):428-35. PMid:11723513. http:// dx.doi.org/10.1590/S0034-89102001000500004
16. Kegel A. Proressive resistance exercise in the functional restration of muscles. Am J Obstet Gynecol. 1948;56:23849. PMid:18877152.

17. Brasil. Ministério da Saúde. secretaria de Gestão Estratégica e Participativa. Considerações Finais. In: Ministério da Saúde, Secretaria de Gestão Estratégica e Participativa. A construção do SUS: histórias da reforma Sanitária e do processo Participativo. Brasília: Ministério da Saúde; 2006. p. 261-278.

18. Dumoulin C, Hay-Smith J. Pelvic floor muscle training versus no treatment, or inactive control treatments, for urinary incontinence in women. Cochrane Database Syst Rev. 2006;(1):CD005654. http://dx.doi. org/10.1002/14651858.CD005654

19. Isherwood PJ, Rane A. Comparative assessment of pelvic floor strength using a perineometer and digital examination. BJOG. 2000;107(8):1007-11. http://dx.doi. org/10.1111/j.1471-0528.2000.tb10404.x

20. Lewis D. Incontinence survey report. In: Getliffe K, Dolman M, editors. Promoting Continence: A clinical and Research resource. London: Bailliere Tindall; 1997.

21. Sobhgol SS, Charandabee SMA. Related factors of urge, stress, mixed urinary incontinence and overactive bladder in reproductive age women in Tabriz, Iran: a cross-sectional study. Int Urogynecol J. 2008;19:367373. PMid:17704857. http://dx.doi.org/10.1007/ s00192-007-0437-2

22. Lopes MHBM, Higa R. Restrições causadas pela incontinência urinária da mulher. Rev Esc Enferm USP. 2006;40(1):34-41. http://dx.doi.org/10.1590/ S0080-62342006000100005

23. Neumann P, Morrison S. Physiotherapy for urinary incontinence. Aust Fam Physician. 2008;37(3):118-21. PMid:18345359.

24. Bo K, Talseth T, Holme I. Single blind, randomised controlled trial of pelvic floor exercises, electrical stimulation, vaginal cones, and no treatment in management of genuine stress incontinence in women. BMJ. 1999;318(7182):487-93. PMid: 10024253 PMCid:PMC27740. http://dx.doi.org/10.1136/ bmj.318.7182.487

25. Herrmann V, Potrick BA, Palma PCR, Zanettini CL, Marques A, Rodrigues NJ. Eletroestimulação transvaginal do assoalho pélvico no tratamento da incontinência urinária de esforço: avaliação clínica e ultra-sonográfica. Rev Assoc Med Bras. 2003;49(4):401-5. PMid:14963592. http://dx.doi.org/10.1590/S0104-42302003000400031

26. Arruda RM, Sousa GO, Castro RA, Sartori MGF, Baracat EC, Girão MJBC. Hiperatividade do detrusor: comparação entre oxibutinina, eletroestimulação funcional do assoalho pélvico e exercícios perineais. Estudo randomizado. Rev Bras Ginecol Obstet. 2007;29(9):252-8. http://dx.doi. org/10.1590/S0100-72032007000900003

27. Barroso JCV, Ramos S, Martins-Costa PRS, Sanches AF, Muller AF. Transvaginal electrical stimulation in the treatment of urinary incontinence. BJU 
Int. 2004;93:319-323. PMid:14764129. http://dx.doi. org/10.1111/j.1464-410X.2004.04608.X

28. Amaro JL, Gameiro MO, Padovani CR. Effect of intravaginal electrical stimulation on pelvic floor muscle strength. Int Urogynecol J Pelvic Floor Dysfunct. 2005;16(5):355-8. PMid:15647885. http:// dx.doi.org/10.1007/s00192-004-1259-0

\section{Correspondence}

\section{Mara Regina Knorst}

Faculdade de Enfermagem, Nutrição e Fisioterapia Av. Ipiranga, 6681, Prédio 12

CEP 90619-900, Porto Alegre, RS, Brasil e-mail: mknorst@pucrs.br 